\title{
Correction to: Behavioural response to illness: development and validation of a self-report measure of illness behaviour avoidance
}

\author{
Inês A. Trindade ${ }^{1,2}$ (D) Helena Pinto ${ }^{1} \cdot$ Ana Allen Gomes $^{1} \cdot$ Simon R. Knowles $^{3} \cdot$ Nuno B. Ferreira $^{4}$
}

๑) Springer Science+Business Media, LLC, part of Springer Nature 2021

\section{Correction: Current Psychology (2021)}

https://doi.org/10.1007/s12144-021-02219-z

The original version of this article contained several printing errors. Changes made in the proofing were not correctly printed. This erratum is presented to fix these errors.

1. Both the incorrect and corrected words in the proof were printed. Changes made in the proofing were now fully implemented.

2. Simon R. Knowles and Nuno B. Ferreira shared co-senior authorship.

3. Author name "Allen-Gomes" has been corrected to "Allen Gomes".

The original article has been corrected.

Publisher's note Springer Nature remains neutral with regard to jurisdictional claims in published maps and institutional affiliations.

The original article can be found online at https://doi.org/10.1007/ s12144-021-02219-z.

Inês A. Trindade

ines.trindade@gu.se

1 CINEICC, Faculty of Psychology and Education Sciences, University of Coimbra, Coimbra, Portugal

2 Department of Molecular and Clinical Medicine, Institute of Medicine, Sahlgrenska Academy, University of Gothenburg, Gothenburg, Sweden

3 Department of Psychological Sciences, School of Health Sciences, Swinburne University of Technology, Swinburne, Australia

4 Department of Social Sciences, School of Humanities and Social Sciences, University of Nicosia, Nicosia, Cyprus 